\title{
The 7th International Congress of Chinese Mathematicians (ICCM 2016)
}

\section{by Yuefei Wang*}

The Seventh International Congress of Chinese Mathematicians (ICCM) will be held from August 6 to 11, 2016 in Beijing. This session of ICCM is jointly hosted by the Academy of Mathematics and Systems Science (AMSS) and the Morningside Center of Mathematics (MCM). It is expected that about 1,500 participants will attend the Congress.

Winners of the Morningside Medal of Mathematics, the Chern Prize and the ICCM International Cooperation Award will be announced at the ceremony on the first day of the Congress. In the following five days, there will be about seven Morningside Lectures, probably at Tsinghua University. Additionally, about 30 plenary lectures and 200 invited lectures, which cover more than 40 topics of mathematics, will be presented at the AMSS or in neighboring buildings.

The International Congress of Chinese Mathematicians is a triennial event that brings together Chinese and overseas mathematicians to discuss the latest research developments in pure and applied mathematics. It was created by Professor Shing-Tung Yau and is funded mainly by the Morningside Center of Mathematics. ICCM is hosted by institutions in mainland China, Hong Kong, and Taiwan, on a rotating basis.

The first Congress was held in December 1998 at the Great Hall of the People, and at the Morningside Center of Mathematics in Beijing. The second Congress took place at Taipei in 2001, the third at Hong Kong in 2004, the fourth at Hangzhou in 2007, the fifth at Beijing in 2010, and the sixth at Taipei in 2013. In 2016, ICCM will return to Beijing again.

\footnotetext{
* Academy of Mathematics and Systems Science, Chinese Academy of Sciences

E-mail: wangyf@math.ac.cn
}

\section{Speakers}

Confirmed speakers of Morningside Lecture include:

Björn Engquist University of Texas at

Camillo de Lellis University of Zurich

Stanley Osher

Wilfried Schmid

Yuri Tsinkle

Edward Witten

University of California, Los Angeles

Harvard University

New York University

Institute for Advanced

Study in Princeton

Confirmed speakers of Plenary Lecture include:

\begin{tabular}{|c|c|}
\hline avid Cai & New York University \\
\hline Raymond Honfu Chan & $\begin{array}{l}\text { Chinese University of Hong } \\
\text { Kong }\end{array}$ \\
\hline Xiuxiong Chen & Stony Brook University \\
\hline I-Liang Chern & National Taiwan University \\
\hline Qiang Du & Columbia University \\
\hline Jianqing Fan & ton University \\
\hline Lei Fu & niversity \\
\hline Fan Chung Graham & y of California, San \\
\hline Xianfeng David Gu & Stony Brook University \\
\hline Xuhu & $\begin{array}{l}\text { Hong Kong University of } \\
\text { Science and Technology }\end{array}$ \\
\hline Lizh & Michigan University \\
\hline Samı & Har \\
\hline Thon & chigan \\
\hline Kai-Wen Lan & nnesota \\
\hline Naichung Conan Leung & $\begin{array}{l}\text { Chinese University of Hong } \\
\text { Kong }\end{array}$ \\
\hline Jun Li & Stanford University \\
\hline
\end{tabular}




\section{The 7th International Congress of Chinese Mathematicians (ICCM 2016)}

\section{by Yuefei Wang*}

The Seventh International Congress of Chinese Mathematicians (ICCM) will be held from August 6 to 11, 2016 in Beijing. This session of ICCM is jointly hosted by the Academy of Mathematics and Systems Science (AMSS) and the Morningside Center of Mathematics (MCM). It is expected that about 1,500 participants will attend the Congress.

Winners of the Morningside Medal of Mathematics, the Chern Prize and the ICCM International Cooperation Award will be announced at the ceremony on the first day of the Congress. In the following five days, there will be about seven Morningside Lectures, probably at Tsinghua University. Additionally, about 30 plenary lectures and 200 invited lectures, which cover more than 40 topics of mathematics, will be presented at the AMSS or in neighboring buildings.

The International Congress of Chinese Mathematicians is a triennial event that brings together Chinese and overseas mathematicians to discuss the latest research developments in pure and applied mathematics. It was created by Professor Shing-Tung Yau and is funded mainly by the Morningside Center of Mathematics. ICCM is hosted by institutions in mainland China, Hong Kong, and Taiwan, on a rotating basis.

The first Congress was held in December 1998 at the Great Hall of the People, and at the Morningside Center of Mathematics in Beijing. The second Congress took place at Taipei in 2001, the third at Hong Kong in 2004, the fourth at Hangzhou in 2007, the fifth at Beijing in 2010, and the sixth at Taipei in 2013. In 2016, ICCM will return to Beijing again.

\footnotetext{
* Academy of Mathematics and Systems Science, Chinese Academy of Sciences

E-mail: wangyf@math.ac.cn
}

\section{Speakers}

Confirmed speakers of Morningside Lecture include:

Björn Engquist University of Texas at

Camillo de Lellis University of Zurich

Stanley Osher

Wilfried Schmid

Yuri Tsinkle

Edward Witten

University of California, Los Angeles

Harvard University

New York University

Institute for Advanced

Study in Princeton

Confirmed speakers of Plenary Lecture include:

\begin{tabular}{|c|c|}
\hline avid Cai & New York University \\
\hline Raymond Honfu Chan & $\begin{array}{l}\text { Chinese University of Hong } \\
\text { Kong }\end{array}$ \\
\hline Xiuxiong Chen & Stony Brook University \\
\hline I-Liang Chern & National Taiwan University \\
\hline Qiang Du & Columbia University \\
\hline Jianqing Fan & ton University \\
\hline Lei Fu & niversity \\
\hline Fan Chung Graham & y of California, San \\
\hline Xianfeng David Gu & Stony Brook University \\
\hline Xuhu & $\begin{array}{l}\text { Hong Kong University of } \\
\text { Science and Technology }\end{array}$ \\
\hline Lizh & Michigan University \\
\hline Samı & Har \\
\hline Thon & chigan \\
\hline Kai-Wen Lan & nnesota \\
\hline Naichung Conan Leung & $\begin{array}{l}\text { Chinese University of Hong } \\
\text { Kong }\end{array}$ \\
\hline Jun Li & Stanford University \\
\hline
\end{tabular}

